\title{
POLA SEBARAN SEDIMEN DASAR BERDASARKAN KARAKTERISTIK MORFOLOGI DAN HIDRO-OSEANOGRAFI MENGGUNAKAN MODEL INTERPOLASI DAN SIMULASI NUMERIK DI PERAIRAN UTARA PULAU SIMEULUECUT
}

\section{DISTRIBUTION PATTERNS OF BOTTOM SEDIMENT BASED FROM MORPHOLOGICAL AND HYDRO-OCEANOGRAPHY CHARACTERISTICS USING INTERPOLATION AND NUMERICAL SIMULATION MODEL IN SIMEULUECUT ISLAND NORTHERN WATERS}

\author{
Ulung Jantama Wisha*, Wisnu Arya Gemilang, Guntur Adhi Rahmawan, Gunardi Kusumah \\ Loka Penelitian Sumber Daya Kerentanan Pesisir, Balitbang KP, Kementerian Kelautan dan \\ Perikanan, JL. Raya Padang-Painan km 16, Bungus, Padang 25245 \\ ${ }^{*}$ Corresponding author email: ulungjantama@gmail.com
}

Submitted: 3 Agustus 2016 / Revised: 31 Maret 2017 / Accepted: 25 April 2017

http://doi.org/10.21107/jk.v10i1.1618

\begin{abstract}
Simeuluecut Island is a conservation area which will be directed as Marine Protected Areas and Wildlife Marine Tourism, it needs to manage the plan of Regional Marine Conservation Area. The purpose of this study was to determine the distribution of bed sediment in the Simeuluecut coastal area based on the study of the bathymetry and the tidal current condition. The method employed is case study method to determine the depth, the distribution pattern of the seabed sediment and physical oceanographic conditions in the Simeuluecut waters qualitatively. The sounding results of bathymetry survey are analyzed spatially, the hydrodynamic condition is simulated by using flow model $\mathrm{fm}$ and tide data is analyzed by admiralty method. The depth of the water ranged from 0-26 meters and slope ranged from $10 \%-15 \%$, obtained three units of surface bed sediment, that are coarse sand, medium sand, and silty sand. Current velocity ranged from 0 to $0,02 \mathrm{~m}^{-1} \mathrm{~s}^{-1}$ at low tide towards the high tide condition and ranged from 0-0,006 m.s $\mathrm{s}^{-1}$ at high tide towards low tide condition, the longshore current velocity ranged from $0.006-0,027 \mathrm{~m}^{-\mathrm{s}^{-1}}$ at the high tide and ranged from 0,001$0,006 \mathrm{~m} \cdot \mathrm{s}^{-1}$ at low tide condition, the MSL value obtained 12,53 m and the tidal range reach 2,2 $\mathrm{m}$, oceanographic conditions has an influence on the bed sediment distribution in the nearshore area and directly affect to the morphology change occurrence in the Simeuluecut waters.
\end{abstract}

Keywords: Bathymetry, hydrodynamic, Sediment, Simeuluecut, Spatial analysis

\begin{abstract}
ABSTRAK
Pulau Simeuluecut merupakan kawasan Konservasi yang nantinya akan diarahkan untuk Daerah Perlindungan Laut (DPL) dan Taman Wisata Bahari (TWB), sehingga diperlukan Managemen Plan Kawasan Konservasi Laut Daerah. Tujuan dari penelitian ini adalah untuk mengetahui sebaran sedimen dasar di pesisir Pulau Simeuluecut berdasarkan kajian batimetri dan arus pasang surut.Metode penelitian yang digunakan adalah metode studi kasus untuk mengetahui kedalaman, pola sebaran sedimen permukaan dasar laut dan kondisi oseanografi fisika di perairan Simeuluecut secara kualitatif. Hasil pemeruman dianalisis secara spasial, kondisi hidrodinamika dimodelkan dengan menggunakan simulasi flow model fm dan pengolahan data pasang surut dengan metode admiralty. Kedalaman perairan berkisar antara 0 - 26 meter dan kelerengan berkisar antara 10\% $15 \%$, diperoleh tiga satuan sedimen permukaan dasar yaitu pasir kasar, satuan pasir sedang dan satuan pasir halus lanauan (silty sand). Kecepatan arus berkisar antara $0-0,02 \mathrm{~m}^{-1} \mathrm{~s}^{-1}$ pada saat surut menuju pasang dan berkisar antara 0-0,006 m.s pada saat pasang menuju surut, untuk kecepatan sepanjang pantai berkisar antara 0,006-0,027 m.s. pada kondisi surut menuju pasang dan berkisar antara 0,001-0,006 m.s. pada kondisi pasang menuju surut, nilai mean sea level
\end{abstract}


(MSL) sebesar 12,53 meter dan tidal range sebesar 2,2 meter, Kondisi oseanografi mempengaruhi distribusi sedimendasar di bibir pantai dan secara langsung berpengaruh terhadap perubahan morfologi di perairan Simeuluecut.

Kata Kunci: Batimetri, hidrodinamika, sedimen, Simeuluecut, spatial analisis

\section{PENDAHULUAN}

Kebijakan pengelolaan yang tertuang dalam Undang-Undang Republik Indonesia Nomor 1 Tahun 2014 tentang Pengelolaan Wilayah Pesisir dan Pulau-Pulau Kecil mengisyaratkan akan peluang pengelolaan kawasan pesisir yang lebih besar kepada pemerintah daerah. Hal ini diindikasikan oleh kesiapan daerah untuk mengidentifikasi serta menginventarisasi peluang sumberdaya potensial yang dapat dikembangkan untuk kemakmuran rakyat. Kondisi ini juga akan menuntut partisipasi serta keseriusan dari daerah untuk menentukan arah pembangunan di wilayah pesisir dan lautan (Monecke et al., 2015)

Langkah awal yang strategis serta antipatif terhadap pengelolaan tersebut adalah dengan menginventarisasi sumberdaya pesisir dengan menggunakan serta merancang data spasial dan atribut menggunakan sistim informasi geografis yang hasil akhirnya diharapkan berupa peta sebaran sumberdaya dan kondisi aktual wilayah pesisir dan lautan. Kabupaten Simeulue dengan lbu Kotanya Sinabang merupakan gugus kepulauan yang terdiri dari 41 buah pulau-pulau besar dan kecil disekitarnya. Secara geografis Simeulue membentang dari Barat ke Timur yang dibatasi/dikelilingi Samudera Hindia serta berbatasan langsung dengan perairan Internasional dengan luas perairan 9.851,796 $\mathrm{km} 2$ dan garis pantai $502.732,22 \mathrm{~km}$ (DKP, 2006). Kondisi ini menyebabkan Kabupaten Simeulue berpotensi mempunyai sumberdaya pesisir dan laut yang bernilai ekonomis tinggi.

Simeuluecut merupakan salah satu pulau kecil yang ada di Pulau Simeulue, dalam rangka upaya pengelolaan sumberdaya pesisir dan lautan yang berkelanjutan maka dengan melalui S.K Bupati Simeulue Nomor 523.1/SK/2006 telah menetapkan Kawasan Konservasi Laut Daerah salah satunya adalah Simeuluecut dimana kawasan ini nantinya akan diarahkan untuk Daerah Perlindungan Laut dan Taman Wisata
Bahari. Berdasarkan hal-hal diatas dipandang perlu untuk menyusun Managemen Plan Kawasan Konservasi Laut Daerah guna menginventarisasi berbagai fenomena yang sedang dan telah terjadi di kawasan laut dalam bentuk data spasial dan atribut, salah satunya adalah kajian terhadap pola sebaran sedimentasi berdasarkan kedalaman batimetri dan pergerakan arus di Simeuluecut dengan harapan dapat memberikan informasi yang berguna dan referensi bagi pengambil kebijakan pembangunan dalam melaksanakan program rehabilitasi dan rekontruksi. Tujuan dari penelitian ini adalah untuk mengetahui sebaran sedimen di sekitar Pulau Simeuluecut berdasarkan kajian batimetri dan arus pasang surut.

\section{MATERI DAN METODE}

Materi utama dalam penelitian ini meliputi data primer dan sekunder. Data primer berupa data kedalaman dan posisinya, sampel sedimen, data pasang-surut, gelombang (tinggi dan periode), dan arus (kecepatan dan arah). Sedangkan data sekunder berupa Peta RBI (Rupa Bumi Indonesia).Metode penelitian yang digunakan adalah metode studi kasus. Studi kasus dalam penelitian ini adalah mengetahui kedalaman, pola sebaran sedimen permukaan dasar laut dan kondisi oseanografi fisika di perairan Simeuluecut.

Sebelum pengumpulan data posisi dilaksanakan, terlebih dahulu dilaksanakan penentuan posisi. Penentuan posisi yang dilaksanakan adalah untuk menentukan posisi kapal pada saat melakukan pengukuran kedalaman perairan (pemeruman) agar kapal tidak keluar dari jalur yang telah ditentukan. Penentuan posisi ini menggunakan sistem navigasi satelit, yaitu GPS (Global Positioning System). Data yang dihasilkan oleh alat ini bersifat digital dan dapat dikirim ke perangkat komputer. Pemeruman (sounding) dimaksudkan untuk mengukur dan mengetahui kedalaman dasar perairan daerah penelitian berikut pola morfologi dasar perairan tersebut. Kegiatan 
ini menggunakan alat perum gema (Echosounder) Singlebeam yang bekerja dengan prinsip pengiriman pulsa energi gelombang suara melalui transmiter transducer menuju ke dasar perairan, kemudian ketika gelombang tadi menyentuh dasar perairan akan dipantulkan dan diterima oleh receiver transducer. Pengambilan data kedalaman menggunakan pola sejajar paralel, yaitu pola dimana arah sounding tegak lurus dan cenderung sejajar dengan garis longitudinal (Gambar 1) atau sesuai dengan pola sounding paralel (Soeprapto, 2001).

Posisi pengambilan sampel sedimen dasar dapat dilihat pada Gambar 2. Pengambilan sample sedimen dasar menggunakan satu unit Sedimen Grab. Sedimen Grab diatur sedemikian rupa sehingga dengan kondisi terbuka diturunkan dengan mengulur tali hingga membentur tanah dasar laut. Saat tali ditarik kembali, secara otomatis mulut sedimen grab akan menggaruk material dibawahnya hingga tertutup. Sedimen grab yang telah memuat material dasar ditarik keatas. Sampel material dasar tersebut dimasukkan ke dalam wadah plastik yang telah diberi tanda untuk di analisa di laboratorium Universitas Andalas, Padang.

Pengukuran arus dan pasang surut dilakukan di Perairan sebelah Timur Pulau Simeuluecut pada koordinat 95 $56^{\prime} 9.40 " E$ dan $2^{\circ} 33^{\prime} 20.11 " \mathrm{~N}$ dengan menggunakan alat ADCP Northek Aquadop Profiler. Pengukuran dilaksanakan pada tanggal 1324 Oktober 2015, dengan kedalaman maksimal $13 \mathrm{~m}$, didapatkan besar dan arah arus total dan juga pasang surut perairan Simeuluecut. Besar dan arah arus tersebut diuraikan berdasarkan komponen kecepatan arus dalam arah $\mathrm{U}$ dan $\mathrm{V}$, dan nilai dari komponen kecepatan arus tersebut diskritisasimenggunakan rumus (Thurman dan Alan, 2004) sebagai berikut:

$$
\begin{aligned}
& U=V_{\text {total }} \sin \left(\frac{\operatorname{Dir} \pi}{180}\right) \\
& V=V_{\text {total }} \cos \left(\frac{\text { Dir } \pi}{180}\right)
\end{aligned}
$$

Dengan nilai $\pi$ adalah 3,14 dan Dir merupakan arah arus yang terukur. Hasil perhitungan Besar kecepatan dan arah arus digunakan untuk melakukan verifikasi permodelan arus pasang surut. Permodelan dilakukan dengan menggunakan simulasi Flow Model Hydrodynamics. Modul hidrodinamika berdasar pada solusi numerik dari persamaan perairan dangkal 2 dimensi, dimana kedalaman di integrasi dan tidak dapat di perkecil dengan bilangan Reynold dari rata-rata persamaan Navier-Stokes. Untuk shallow water equation pada koordinat kartesius, digunakan persamaan CFL (courant-friendrich-levy) yang di definisikan sebagai:

$$
\left.\mathrm{CFLHD}=(\sqrt{g h+|U|}) \frac{\Delta t}{\Delta x}+(\sqrt{g h+|V|}) \frac{\Delta t}{\Delta y}\right)
$$

Dimana $\mathrm{h}$ adalah total dari kedalaman, $\mathrm{u}$ dan $v$ adalah komponen kecepatan pada arah $\mathrm{x}$ dan y, g adalah percepatan gravitasi, $\Delta \mathrm{x}$ dan $\Delta y$ adalah skala karakteristik panjang pada arah $\mathrm{x}$ dan $\mathrm{y}$ untuk sebuah elemen dan $\Delta \mathrm{t}$ adalah interval tahapan waktu. Skala karakteristik panjang, $\Delta \mathrm{x}$ dan $\Delta \mathrm{y}$, di berikan oleh rata-rata panjang minimum untuk setiap elemen dan kedalaman perairan dan komponen kecepatan di evaluasi pada pusat elemen.

Analisa harmonik pasang surut dilakukan dengan metode admiralty dengan tujuan untuk mendapatkan konstanta harmonic pasang surut yang meliputi Amplitudo (A), M2, S2, K1, O1, N2, K2, P1, M4, MS4, nilai fase ( $\mathrm{g}$, dalam derajat) dan Tipe Pasang Surut (Ongkosongo dan Suyarso, 1989).

\section{HASIL DAN PEMBAHASAN}

Peta posisi titik fiks perum menunjukkan bahwa jarak antar titik-titik fiks perum pada suatu lajur pemeruman lebih rapat dari interval lajur perum, kerapatan antar titik- titik fiks perum dan interval lajur perum memang telah diperhitungkan jaraknya sehingga diharapkan mampu menghasilkan data kedalaman yang baik, sesuai dengan pendapat Poerbandono dan Djunarsjah, (2005) bahwa jarak antara titik-titik fiks perum pada suatu lajur pemeruman setidaktidaknya sama dengan atau lebih rapat dari interval lajur perum.

Hasil pengukuran kedalaman (kedalaman terbaca dan yang telah terkoreksi transducer) adalah kedalaman terhadap air laut saat pengukuran, sedangkan garis kontur kedalaman dalam peta batimetri adalah kedalaman dengan bidang acuan muka air laut rata-rata atau Duduk Tengah (DT) atau dalam bahasa Inggris adalah Mean Sea Level (MSL). Untuk menggambarkan garis kontur dengan acuan MSL maka perlu dihitung nilai MSL terlebih dahulu. 


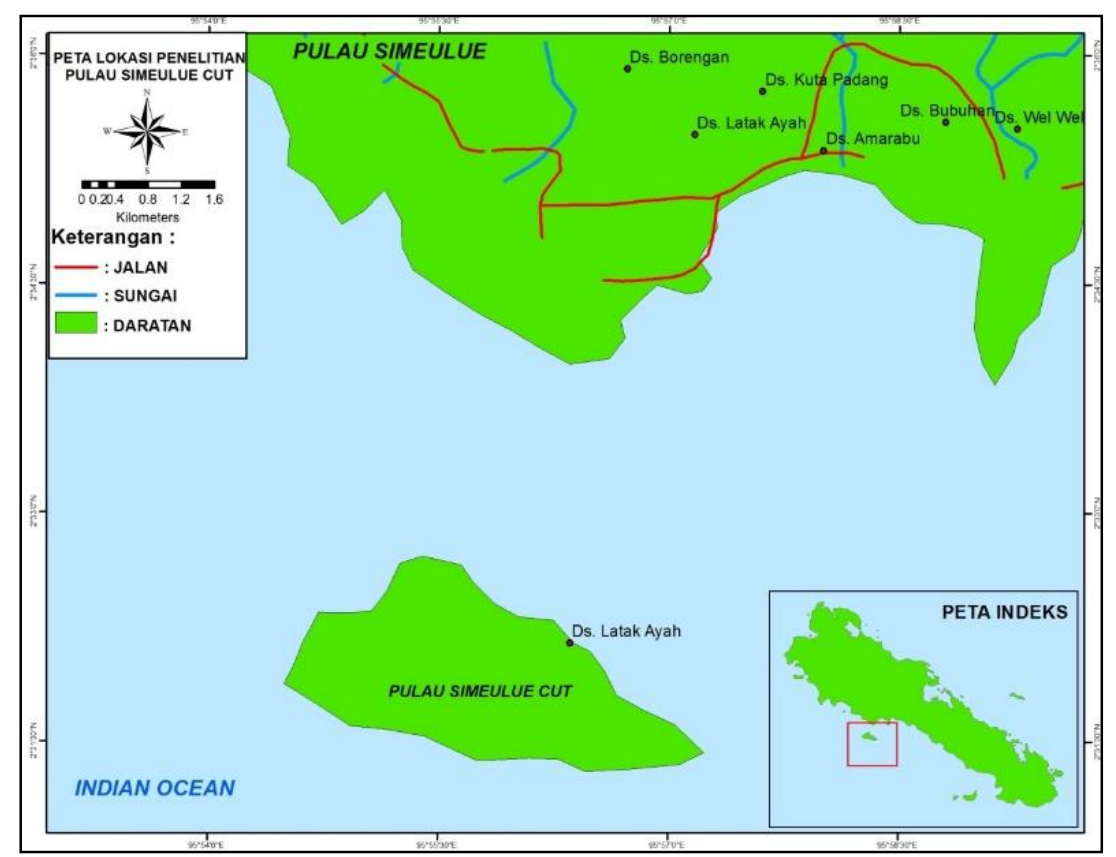

Gambar 1.Peta Lokasi Penelitian

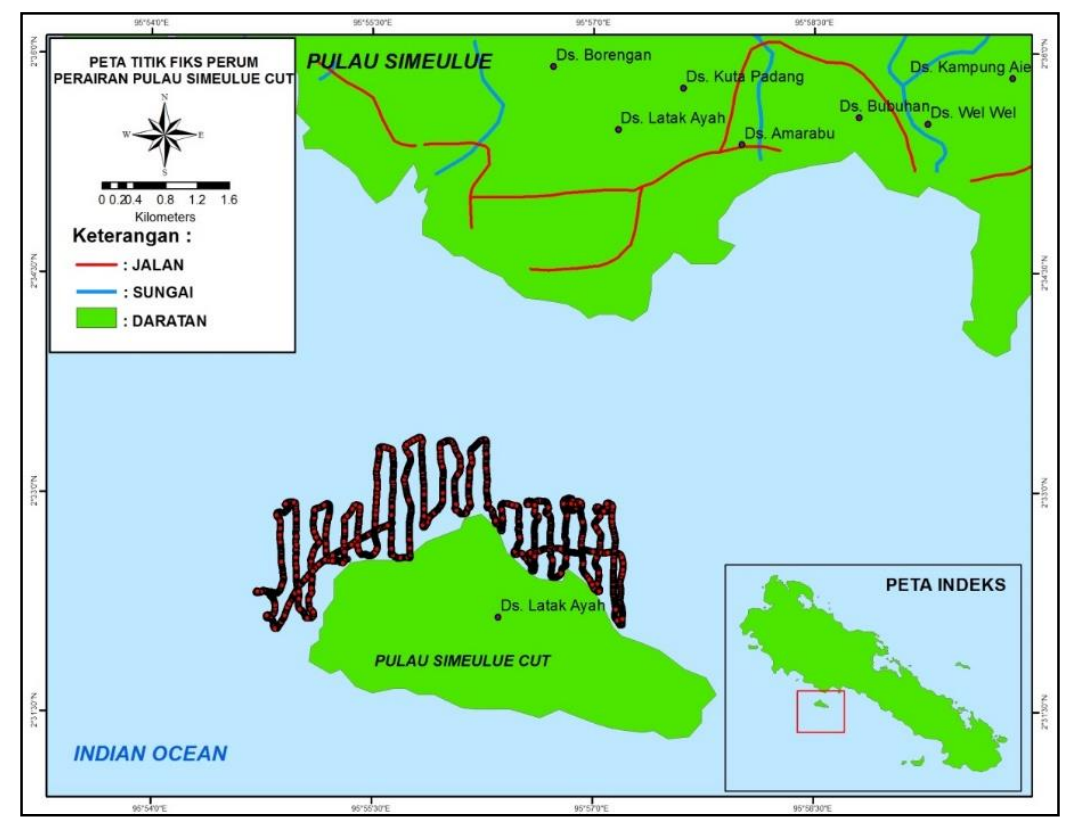

Gambar 2. Peta Titik Fiks Perum Perairan Pulau Simeuluecut

Pada penelitian ini nilai MSL yang didapat yaitu 129,3 cm dari nol palem (Gambar 9). Nilai MSL yang didapat tersebut selanjutnya digunakan sebagai koreksi pasang surut. Pada penelitian ini data kedalaman laut sebenarnya atau data kedalaman terkoreksi pasut diperoleh dari perhitungan kedalaman yang dihasilkan alat perum gema dikurangi dengan koreksi pasut, koreksi pasut yaitu ketinggian pasut saat pengambilan data dikurangi MSL dan kedalaman muka surutan di bawah MSL (Zo).

Pada Gambar 2 menunjukkan titik fiks perum terlihat kurang begitu rapi dikarenakan dalam pengambilan titik sampling pemeruman mengalami berbagai kendala antara lain wahana apung (kapal) yang digunakan 
memiliki kemampuan gerak dan kestabilan yang terbatas, sehingga laju yang dilalui kurang sesuai dengan bentuk jalur pemeruman yang telah di rancang (yang direncanakan). Kedalaman batimetri (Gambar 3) memperlihatkan kedalaman dari perairan Pulau Simeuluecut pada batas wilayah studi penelitian (medan pemeruman) berkisar antara $0-26$ meter. Analisis spasial digunakan untuk menampilkan hasil pemeruman (survey batimetri) (Permana dan Handayani, 2010), sehingga dapat lebih mempermudah dalam interpretasi kondisi batimetri terkini perairan Simeuluecut.
Gambar 4, 5, 6, dan 7 merupakan gambar profil kedalaman perairan Pulau Simeuluecut, untuk mengetahui kisaran kemiringan lereng pantai terhadap morfologi bawah laut. Berdasarkan profil kedalaman yang diambil dari garis tegak lurus pantai terhadap laut sebanyak 4 lintasan menunjukkan bahwa kelerengan berkisar antara 10\% - 15\%, dapat diartikan kemiringan tersebut masuk dalam kelas landai hingga cukup curam (Syah dan Hariyanto, 2013) (Gambar 8).

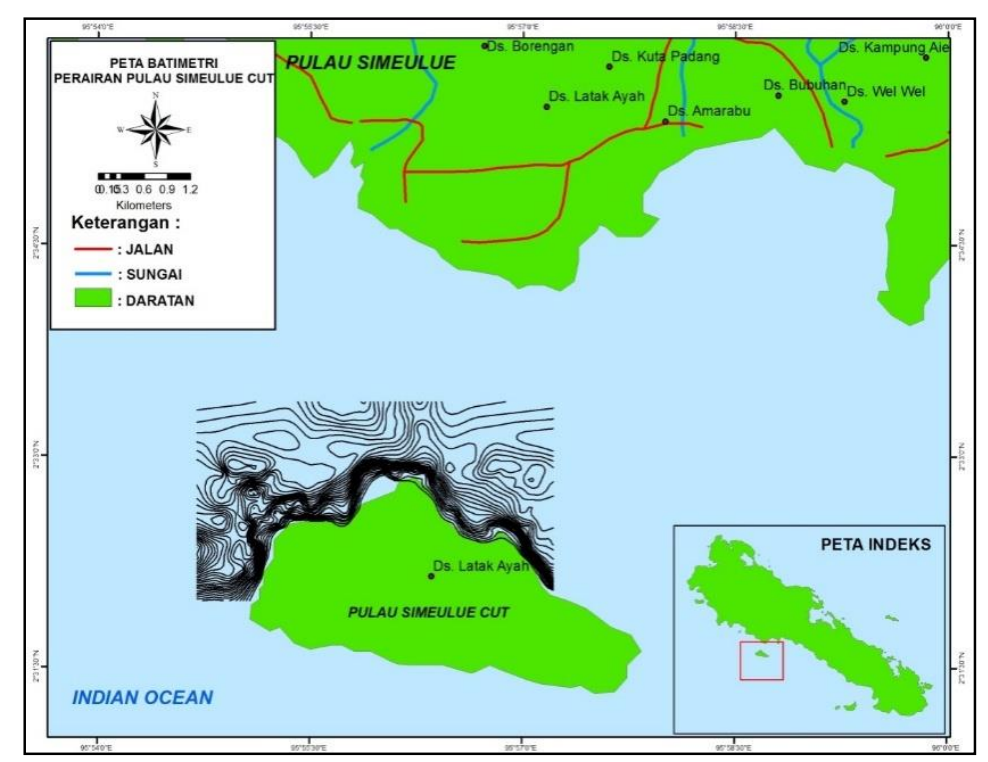

Gambar 3. Peta Batimetri Perairan Pulau Simeuluecut

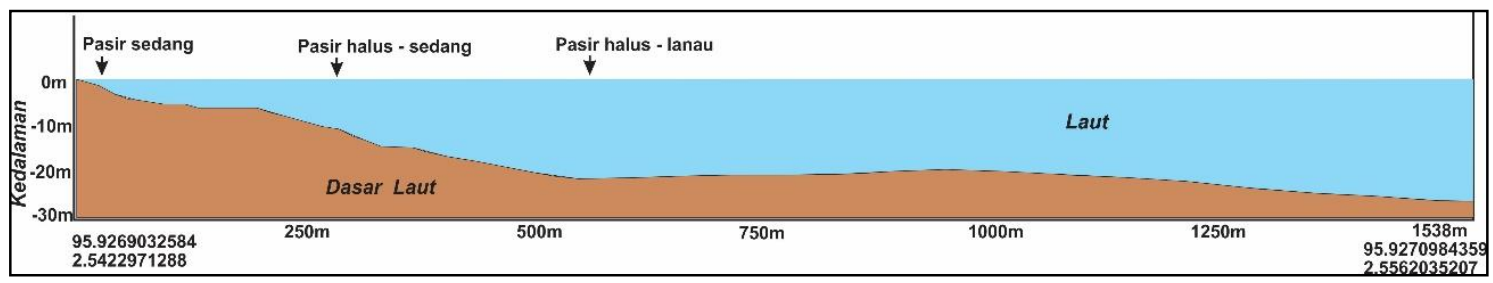

Gambar 4. Profil Kedalaman (P1)

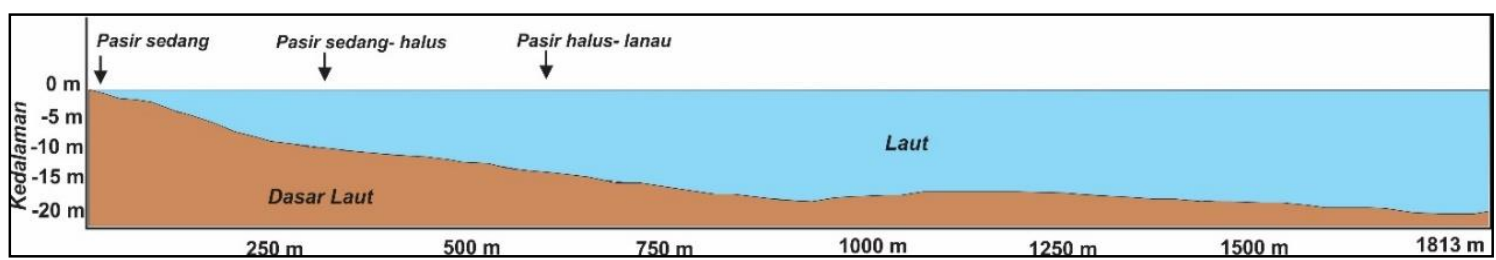

Gambar 5. Profil Kedalaman (P2) 


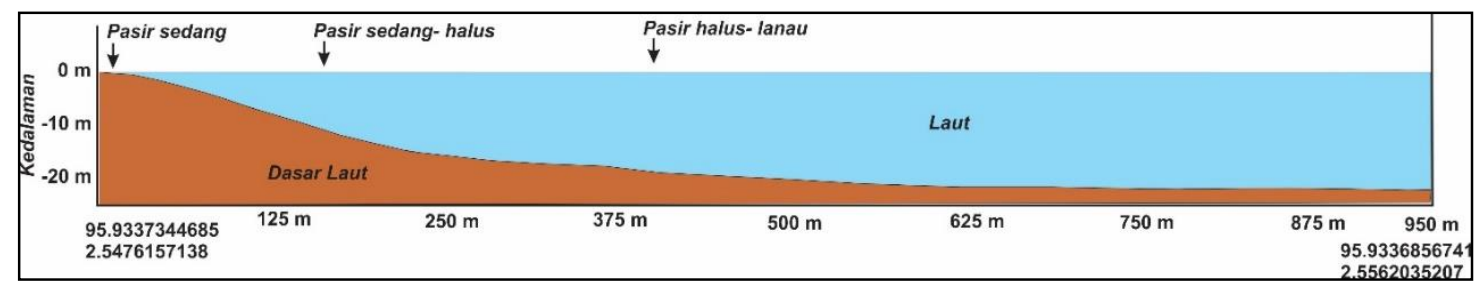

Gambar 6. Profil Kedalaman (P3)

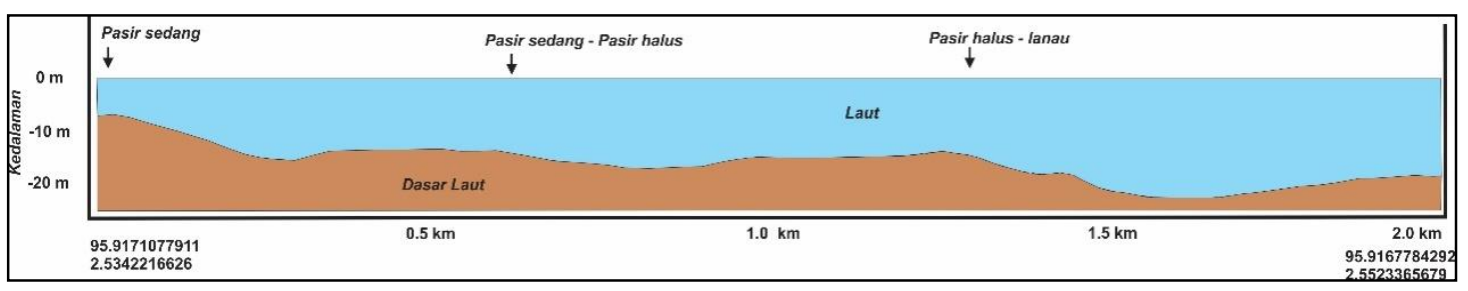

Gambar 7. Profil Kedalaman (P4)

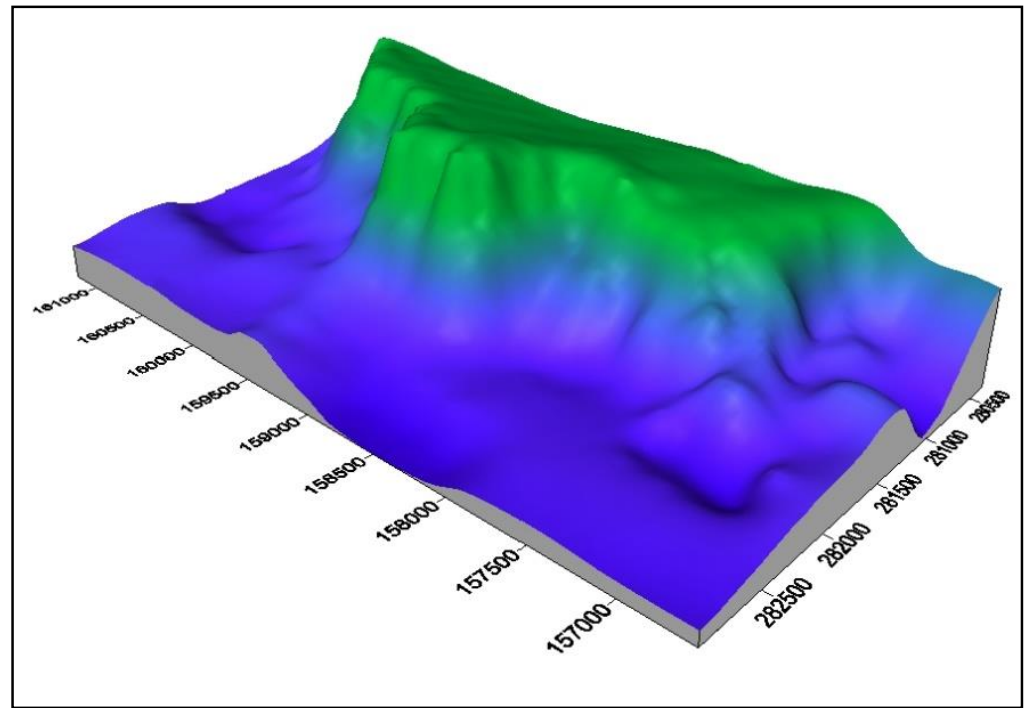

Gambar 8. Topografi dasar perairan Simeuluecut

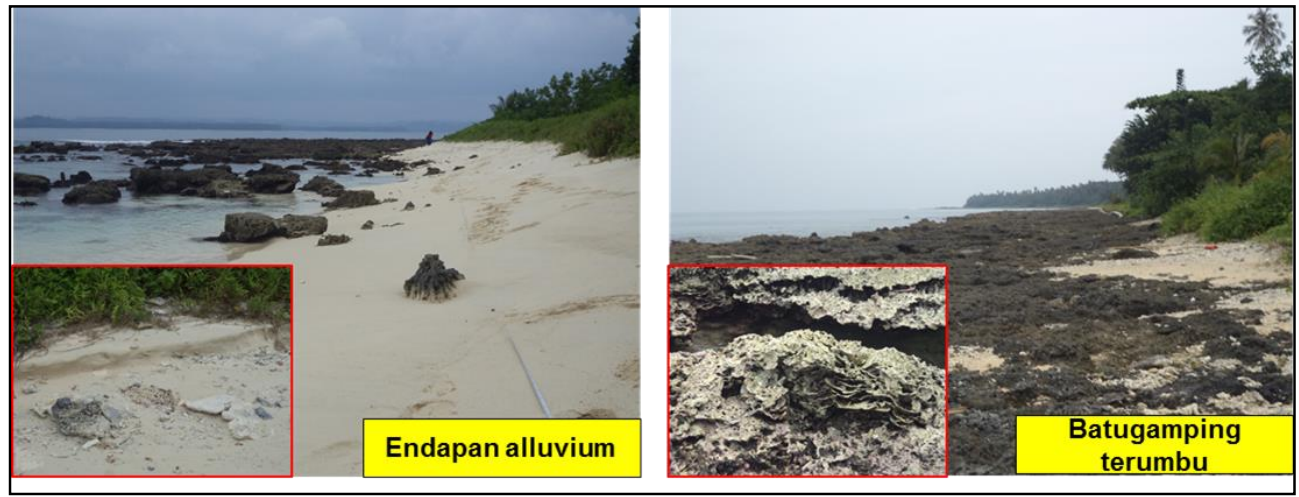

Gambar 9. Litologi penyusun Pulau Simeuluecut 
Hasil analisis sedimen permukaan dasar di perairan Simeuluecut, diperoleh tiga satuan sedimen yaitu pasir kasar, satuan pasir sedang dan satuan pasir halus-lanauan (silty sand). Berdasarkan pada peta geologi lembar Sinabang (Endharto M dan Sukido, 1994) wilayah pulau Simeuluecut terbagi atas tiga kelompok batuan penyusun yaitu $\mathrm{Qa}$ (Aluvium) yang tersusun atas litologi berupa lumpur, pasir, lempung, kerikil dan kerakal yang belum terkompakkan, litologi kedua yaitu Qps (batugamping terumbu) yang terdiri dari batugamping koral, kalkarenit dan kalsilutit.

Bagian dari tengah pulau Simeuluecut tersusun oleh Tmpd (Formasi Dihit) yang terdiri dari arenit berlapis dengan sisipan batulanau dan batugamping. Proses sedimentasi merupakan proses pembentukan sedimen atau batuan sedimen yang diakibatkan oleh pengendapan dari material pembentuk atau asalnya pada suatu tempat yang disebut dengan lingkungan pengendapan berupa sungai, muara, danau, delta, estuaria, laut dangkal sampai laut dalam (Pettijohn, 1975).

Proses sebaran substrat sedimen yang ada dilingkungan perairan Simeuluecut tidak terlepas dari hasil rombakan atau pelapukan litologi penyusun pulau Simeuluecut yang tertransport baik oleh media air maupun angin yang kemudian terendapkan (Henstock et al., 2011). Sebaran litologi wilayah Simeuluecut bagian depan yang berhadapan dengan Pulau Simeulue tersusun atas endapan alluvium berupa lumpur, pasir serta pecahan cangkang. Sedangkan bagian tepi Simeuluecut yang berhadapan langsung dengan samudera hindia tersusun atas material batugamping terumbu (Vina-Finzi dan Situmorang, 1989).

Sebaran jenis sedimen pada lokasi penelitian relative bervariasi, hal ini dapat diketahui dari gambar peta sebaran sedimen permukaan laut (Gambar 9). Di daerah pantai didominasi oleh sedimen pasir yang bercampur dengan pecahan terumbu karang maupun cangkang organisme, hal ini dimungkinkan karena besarnya ukuran butir sedimen di daerah tersebut cenderung resisten terhadap gerakan arus sehingga tidak terangkut mengikuti kecepatan dan arah arus. Sesuai dengan pendapat Poerbandono dan Djunarsjah (2005) yang menyatakan bahwa sedimen yang berukuran besar (misalnya: pasir kasar dan kerikil maupun pecahan karang atau cangkang) cenderung resisten terhadap gerakan arus. Jika kekuatan arus cukup besar, sedimen tersebut cenderung terangkut dengan kontak yang kontinu (menggelinding, meluncur atau melompatmelompat) dengan dasar perairan.

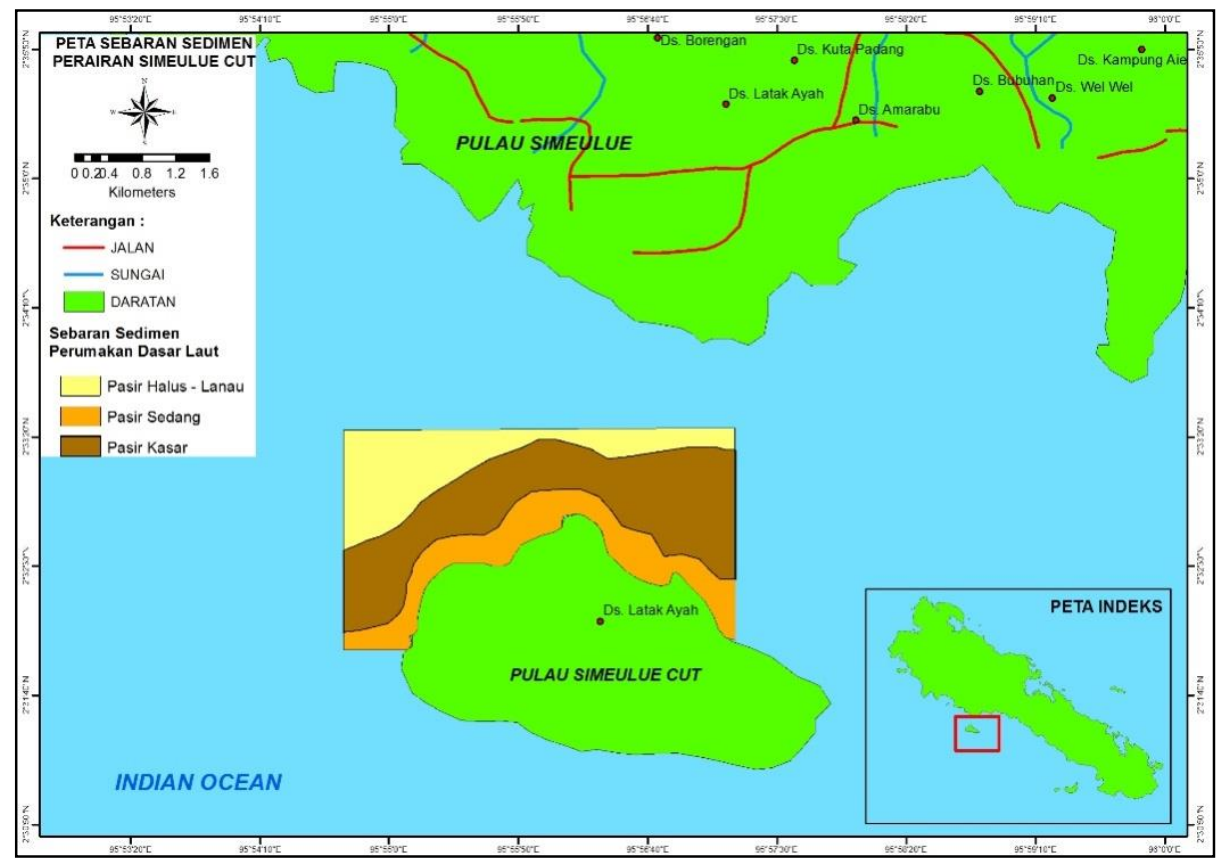

Gambar 10. Peta Sebaran Sedimen Perairan Simeuluecut 
Transport sedimen sepanjang pantai merupakan gerakan sedimen di daerah pantai yang disebabkan oleh gelombang dan arus yang dibangkitkan (Komar, 1993). Transport sedimen ini terjadi antara gelombang pecah dan garis pantai akibat sedimen yang dibawanya (Ladage et al., 2006). Hal tersebut dimungkinkan juga karena pengaruh gelombang dari laut. Hal ini menyebabkan terjadinya turbulensi yang membawa material dari dasar pantai (Wisha et al., 2014), sehingga erosi daerah pantai akan lebih aktif akibat gelombang. Kondisi itu menyebabkan pada daerah pantai Simeuluecut terendapkan substrat sedimen yang berukuran tidak seragam didominasi oleh endapan pasir berukuran kasar hingga sedang yang bercampur dengan pecahan terumbu dan cangkang.

Sedimen yang berukuran lebih kecil dan lebih halus dibandingkan dengan bagian tepi pantai misalnya pasir halus hingga pasir lanau cenderung terangkut sebagai suspensi dengan kecepatan dan arah yang mengikuti kecepatan arah dan arus. Hal ini disebabkan karena pengaruh kondisi arus yang tenang dan akan mulai mengendapkan ketika kecepatan aliran mulai merendah.Menurut Wibisono (2005) apabila sedimen terdiri dari partikel dengan ukuran seragam, dikatakan sedimen tersebut dalam kondisi sangat tersortir (well sorted). Jadi sedimen yang sangat tersortir adalah sedimen yang terdiri dari partikel-partikel dengan kisaran ukuran yang sangat terbatas, sedangkan ukuran partikel yang lain telah tersingkir oleh kekuatan mekanis yang dalam hal ini berupa ombak dan arus. Hal tersebut terbukti sebaran sedimen pada bagian tengah hingga tepian perairan Simeuluecut didominasi oleh substrat sedimen pasir halus hingga lanau dengan ukuran butir relative seragam. Sebaliknya sedimen yang kurang mengalami sortasi (poorly sorted sediment) terdiri dari berbagai ukuran partikel yang menunjukkan kecilnya pengaruh tenaga mekanis yang dikenakan untuk mensortir berbagai ukuran partikel.

Hasil pengolahan data arus dengan menggunakan permodelan diverifikasi dengan data arus hasil pengukuran dilapangan dan di dapatkan nilai RMSE sebesar $11,7 \%$. Dari hasil perhitungan error dan verifikasi hasil model terlihat bahwa grafik kecepatan arus hasil model dan data lapangan memiliki fluktuasi kecepatan arus yang hamper sama (Gambar 10) dan fasa pasang surut antara hasil permodelan dengan data lapangan hampir sama namun pada akhir simulasi terdapat anomaly fasa pasang surut dan cenderung lebih fluktuatif tunggang pasang surutnya, hal tersebut diakibatkan oleh pembentukan pasang surut dan gelombang yang terjadi secara bersamaan (Gambar 11), menurut Wisha et al. (2015) pasang surut terjadi bersamaan dengan gelombang dan menyebabkan muka air laut yang terjadi akan relative tidak konstan.

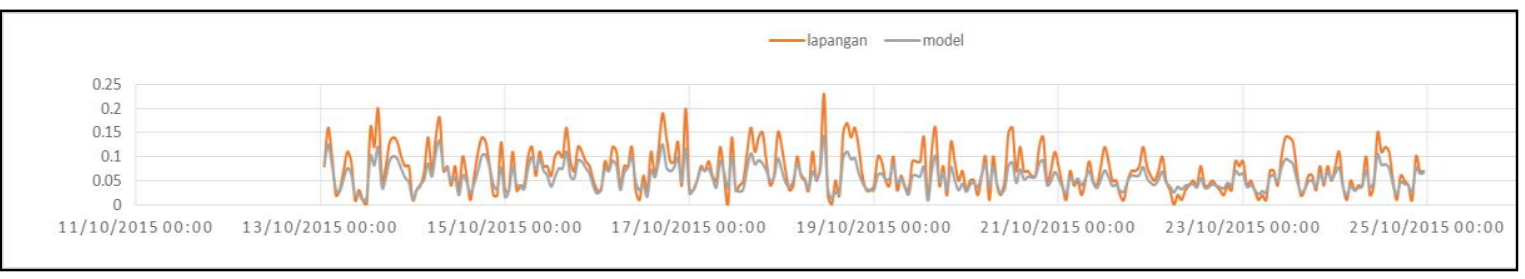

Gambar 10. Verifikasi hasil model dengan data arus

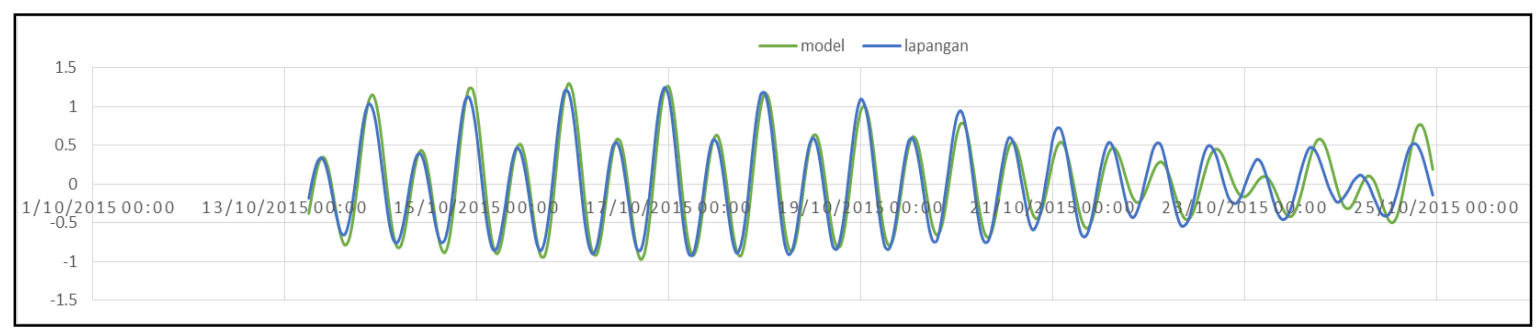

Gambar 11. Fasa pasang surut antara hasil permodelan dengan data lapangan 
Pada kondisi pasang menuju surut (Gambar 12) dinamika arus bererak dominan dari Samudera Hindia yang masuk melalui celah perairan diantara daratan Pulau Simeulue dan Pulau Simeuluecut, arus bergerak menuju ke darat dengan kecepatan berkisar antara 0-0,006 m/s. pada Pulau Simeulue bagian utara, Barat dan tenggara merupakan kecepatan arus yang paling tinggi, akibat adanya proses deformasi gelombang yang terjadi Karena posisi Pulau Simeulue yang langsung berbatasan dengan Samudera Hindia.

Pada kondisi menuju surut ini arus bergerak menyusur pantai dan pada prosesnya arus bergerak membawa massa air yang didalamnya juga terangkut sedimen dan material-material lain yang ada di sekitar perairan tersebut. Di wilayah yang berkepatan arus tinggi, mekanisme transport juga tinggi sehingga cenderung terjadi abrasi diwilayah tersebut, sedangkan wilayah yang berkecepatan arus lemah sedimen tersuspensi akan mudah mengendap, karena kurangnya energi transport oleh arus dan pasang surut (Wisha dan Aida, 2016).
Di bagian Timur laut Pulau Simeuluecut arus terlihat sangat lemah bila dibandingkan sekitarnya, hal ini desebabkan oleh adanya pengurangan energi yang diakibatkan oleh meningkatnya gesekan dasar saat arus dari Samudera Hindia menabrak Pulau Simeuluecut dan terdifraksi dan energinya melemah pada bagian Timur laut sehingga angkutan sedimen sangat rendah dibagian tersebut, hal tersebut sesuai dengan kondisi perairan pada saat dilakukan survei penelitian, terlihat bahwa bagian Timur Laut Pulau Simeuluecut lebih jernih dan sedikit terjadi transport sedimen.

Berbeda dengan dinamika arus pasang surut pada kondisi surut menuju pasang (Gambar 13), arah arus bergerak menjauhi daratan dengan kecepatan berkisar antara 0-0,02 $\mathrm{m} / \mathrm{s}$, dinamika massa air yang bergerak bolak-balik menyebabkan transport bahan organik maupun sedimen menjadi lebih baik, dan di beberapa wilayah yang dilewati arus lemah akan terjadi penupukan sedimen dan bahan organik tersebut. Hal tersebut sesuai dengan hasil penelitian oleh Hertanti (2014) yang menyatakan bahwa distribusi bahan organik bergantung pada karakteristik hidrodinamika di suatu peraran.

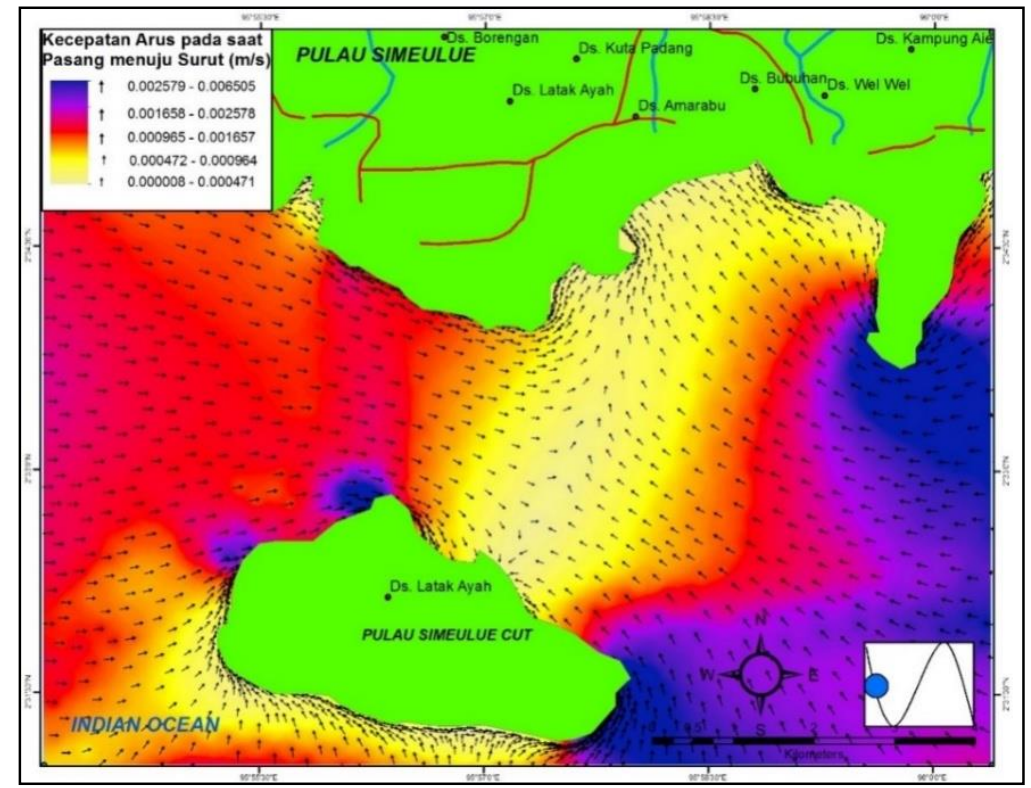

Gambar 12. Hidrodinamika Perairan Simeuluecut pada saat Pasang menuju Surut 


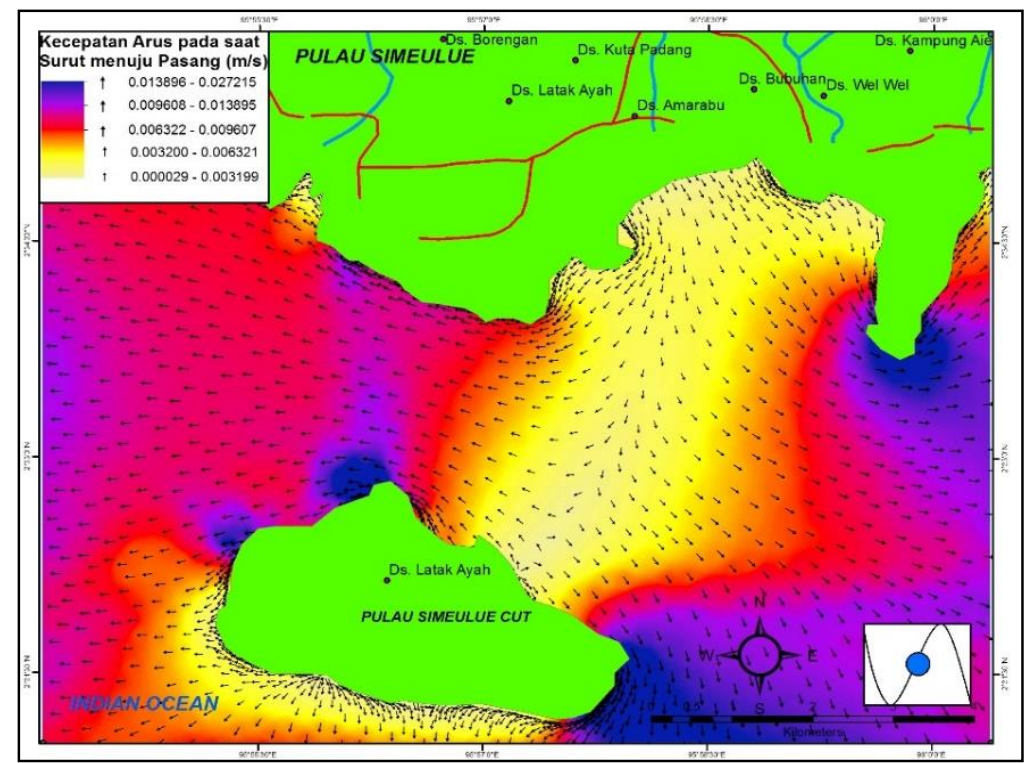

Gambar 13. Hidrodinamika perairan Simeuluecut pada saat surut menuju pasang

Pengukuran pasut di perairan Simeuluecut digunakan untuk mengetahui nilai komponen-komponen harmonik yang dapat digunanakan untuk menentukan tipe pasang surut (Tabel 3), menghitung nilai MHHWS, MLHWN, MLLWN, MLLWS berdasarkan analisis Indian Spring Low Water (Gambar 12), serta menghitung nilai MSL ( $\mathrm{s} 0$ ). Nilai MSL yang didapat yaitu 12,53 meter dari nol kedalaman alat ADCP yang berarti bahwa ketinggian rata-rata permukaan laut dalam 12 hari pengamatan adalah 12,53 meter. Nilai
MSL yang diperoleh selanjutnya digunakan sebagai koreksi terhadap nilai kedalaman hasil pemeruman batimetri (Mihardja dan Setiadi, 1989). Menurut Miharja dan Setiadi (1989) datum referensi pasut yang digunakan ada 3 macam, yaitu nilai duduk tengah, muka surutan dan air tertinggi rata-rata. Tunggang pasut hasil analisa sebesar 2,84 meter, range pasut tersebut tidak terlalu besar (Pietrzak et al., 2007), dan bergerak fluktuatif 2 kali pasang dan 2 kali surut.

Tabel 3. Nilai konstituen pasang surut

\begin{tabular}{ccc}
\hline Konstituen & Amplitudo & Beda fasa \\
\hline M2 & 0.62 & 92.85 \\
S2 & 2.62 & 220.89 \\
N2 & 0.32 & 1.19 \\
K2 & 2.31 & 119.45 \\
K1 & 1.42 & 133.58 \\
O1 & 0.1 & 102.65 \\
P1 & 1.49 & -60.85 \\
M4 & 0.01 & 60.56 \\
MS4 & 0.01 & 200.92 \\
SO & 12.53 & MSL \\
\hline Tipe Pasut (F) & 0.469135802 & Campuran Condong \\
\hline
\end{tabular}




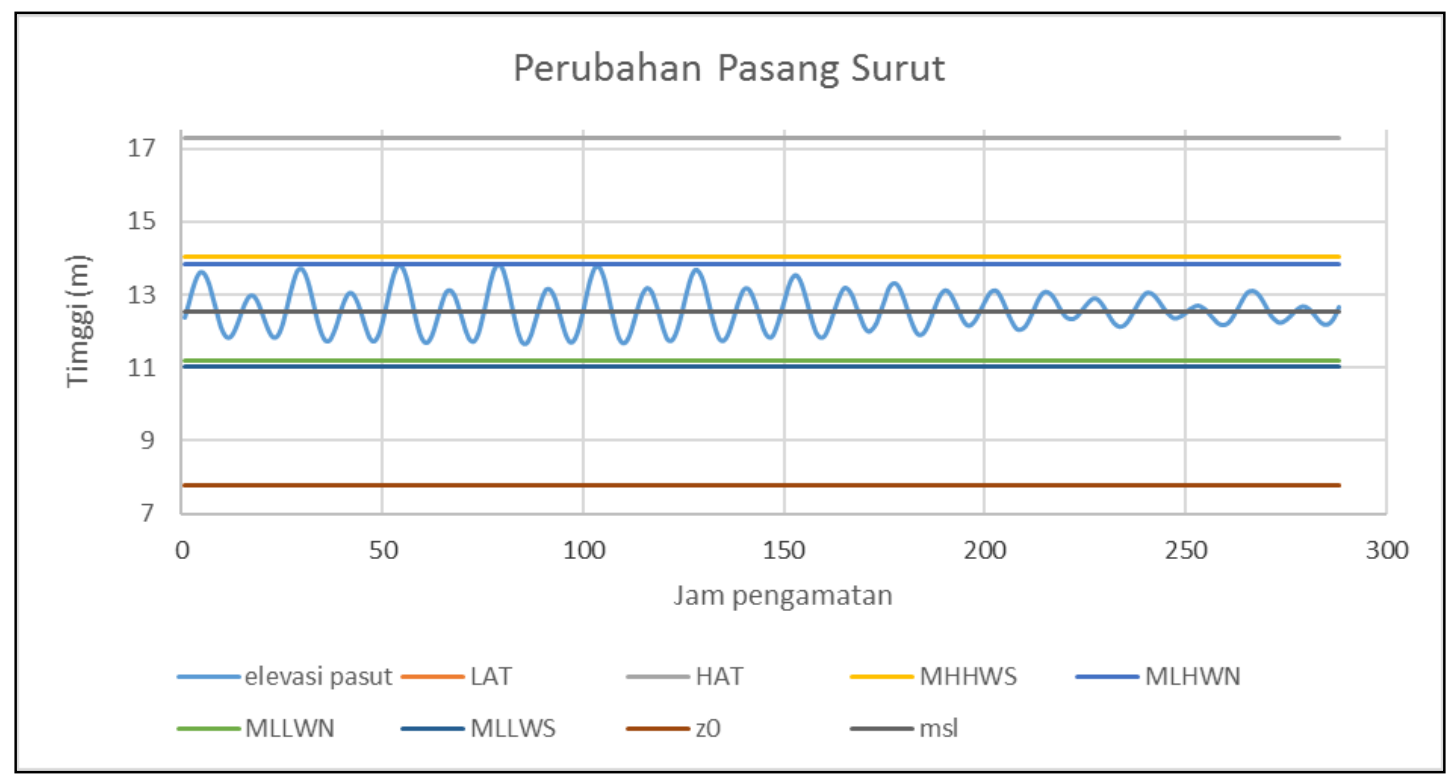

Gambar 14. Grafik perubahan pasang surut perairan Simeuluecut

\section{KESIMPULAN}

Dari hasil penelitian dapat disimpulkan bahwa kedalaman di perairan Simeluecut antara 0-26 meter dengan kategori kemiringan landai hingga cukup terjal, sebaran sedimen di Simeluecut terdiri dari 3 jenis yaitu pasir kasar, pasir sedang, dan pasir lanau. Endapan pasir kasar berada pada kedalaman rata-rata 10 meter, sedangkan pasir sedang berada sampai kedalaman $20 \mathrm{~m}$, dan pasir lanau rata-rata pada kedalaman $25 \mathrm{~m}$. Di wilayah dengan kecepatan arus tinggi, mekanisme transport juga tinggi sehingga cenderung terjadi abrasi diwilayah tersebut, sedangkan wilayah yang berkecepatan arus lemah, sedimen yang teraduk akan mudah mengendap. Pola arus pasang surut memengaruhi mekanisme transport dan pengadukan sedimen dasar, transportasi sedimen yang terjadi disetiap perubahan pasang surut menyebabakan perubahan morfologi dasar perairan.

\section{UCAPAN TERIMA KASIH}

Ucapan terima kasih kepada Loka Penelitian Sumber daya dan Kerentanan Pesisir (LPSDKP) dan P3SDLP atas DIPA anggaran APBNP 2015, serta semua pihak yang memebantu daqlam pelaksanaan penelitian di Pulau Simeulue Oktober 2015.

\section{DAFTAR PUSTAKA}

Endharto, M., \& Sukido (1994). Peta Geologi Lembar Sinabang, Sumatra. Pusat Penelitian dan Pengembangan Geologi, Bandung.

Henstock, T., Ladage, S., Hirata, K., Fujiwara, T., \& Hananto, N. D. (2011). Struktur geologi busur muka aceh: kajian batimetri dan seismik kawasan lepas pantai aceh sumatra indonesia. In proceedings Joint Convention HAGI-IAGI 2011, Makassar, 26-29 September 2011.

Hertanti, D. P., Yusuf, M., Maslukah, L. (2014). Sebaran Kandungan Bahan Organik Total di Perairan Muara Sungai Porong Kabupaten Sidoarjo. Jurnal Oseanografi, 3(4),610-617.

Komar, P. D. (1998). Beach processes and sedimentation. Second Edition. Printice Hall. New Jersey, 539 pp.

Ladage, S., Gaedicke, C., Barckhausen, U., Heyde, I., Weinrebe, W., Flueh, E. R., \& Djajadihardja, Y. (2006). Bathymetric survey images structure off Sumatra. Eos, Transactions American Geophysical Union, 87(17), 165-168. Doi: $10.1029 / 2006$ EO17000.

Mihardja, D. K., \& Setiadi, R. (1989). Analisis Pasang Surut di Daerah Cilacap dan Surabaya. Pasang-surut. ASEANAustralia cooperative programs on marine science (Project I: Tides and tidal phenomena), Puslitbang Oseanologi-LIP\}, Jakarta, 201-230. 
Monecke, K., Templeton, C. K., Finger, W., Houston, B., Luthi, S., McAdoo, B. G., \& Hood, N. (2015). Beach ridge patterns in West Aceh, Indonesia, and their response to large earthquakes along the northern Sunda trench. Quaternary Science Reviews, 113, 159-170.

Doi: 10.1016/j.quascirev.2014.10.014.

Permana, H., \& Handayani, L. (2010). Studi awal pola struktur busur muka aceh, Sumatra bagian utara (Indonesia): Penafsiran dan Analisis Peta Batimetri. Jurnal Geologi Kelautan, 8(3), 105118.

Pettijohn, F. J. (1975). Sedimentary Rock: Harper \& Row Publishers, New YorkEvanston-San Fransisco-London.

Pietrzak, J., Socquet, A., Ham, D., Simons, W., Vigny, C., Labeur, R. J., \& Vatvani, D. (2007). Defining the source region of the Indian Ocean Tsunami from GPS, altimeters, tide gauges and tsunami models. Earth and Planetary Science Letters, 261(1), 49-64. Doi: 10.1016/j.epsl.2007.06.002.

Poerbandono \& Djunarsjah, E. (2005). Survei Hidrografi. Refika Aditama. Bandung. $166 \mathrm{pp}$.

Satriadi, A. (2012). Studi Batimetri dan Jenis Sedimen Dasar Laut di Perairan Marina Semarang, Jawa Tengah.Buletin Oseanografi Marina, 1(1), 53-62.

Surinati, D. (2009). Kondisi oseanografi fisika perairan barat sumatera (pulau simeulue dan sekitarnya) pada bulan agustus 2007 pasca tsunami desember 2004. Makara Sains, 13(1), 17-22.
Syah, M. W., \& Haryanto, T. (2013). Klasifikasi kemiringan lereng dengan menggunakan pengembangan sistem informasi geografis sebagai evaluasi kesesuaian landasan pemukiman berdasarkan undang-undang tata ruang dan metode fuzzy. Teknik Pomits, 10(10), 1-6.

Thurman, H. V., \& Alan P. T. (2004). Intoductory Oceanography, 10ed, Pearson Education, inc. New Jersey $188 \mathrm{pp}$.

Triadmodjo, B. (2014). Perencanaan Bangunan Pantai. Beta Offset, Yogyakarta.

Vita-Finzi, C., \& Situmorang, B. (1989). Holocene coastal deformation in Simeulue and Nias, Indonesia. Marine Geology, 89(1-2), 153-161. Doi: 10.1016/0025-3227(89)90031-5.

Wibisono, M. S. (2005). Pengantar IImu Kelautan. Grasindo. Jakarta. $226 \mathrm{hlm}$.

Wisha, U. J., Yusuf, M., \& Maslukah, L. (2014). Sebaran Muatan Padatan Tersuspensi dan Kelimpahan fitoplankton di Perairan Muara Sungai Porong, Kab. Sidoarjo. Jurnal oseanografi, 3(3),454-461.

Wisha, U. J., Semeidi, H., \& Joko, P. (2015). Hydrodynamics of Banten Bay During Transitional Seasons (AugustSeptember). IImu Kelautan, 20(2), 101-112.

Doi: 10.14710/ik.ijms.20.2.101-112.

Wisha, U. J., \& Aida, H. (2016). Analysis of Tidal Range and Its Effect on Distribution of Total Suspended Solid (TSS) in the Pare Bay Waters. Jurnal Kelautan, 9(1). 23-31. 